\title{
'Roots'?: the relationship between the global and the local within the Extreme Metal scene
}

\author{
KEITH HARRIS
}

Music's 'malleability' (Taylor 1997) has always facilitated its export and import from one location to another. Indeed, such processes are central to the creation and dissemination of new musical forms. Yet in our contemporary globalised world, such processes occur ever more extensively and rapidly giving rise to new forms of appropriation and syncretism. Record companies from the developed world find new audiences in the developing world (Laing 1986). Musicians from the West appropriate non-Western music, sometimes collaboratively (Feld 1994; Taylor 1997). Non-Western musicians and musicians from subaltern groups within the West create new syncretic forms drawing on both Western and non-Western music (Mitchell 1996; Lipsitz 1994, Slobin 1993). The resulting 'global ecumene' produces considerable 'cultural disorder' (Featherstone 1990, p. 6) whose results cannot easily be summarised.

Yet whilst there is no privileged standpoint from which to make an overall judgement on the results of the globalisation of music, it is important to attempt to find an analytical perspective that would enable us to relate particular cases to global processes. Certain global musics may produce so many knotty paradoxes that analysis may lose site of the general picture within the complexities of the particular. In this paper I want to examine one particular paradox, that of the career of the Brazilian Death Metal band Sepultura. I want to show how analysing their career through an examination of the 'scene' through which they travelled allows us to appreciate the unique way in which they responded to globalisation, without losing site of the global flows of capital that structured their career.

\section{Sepultura and the Extreme Metal scene ${ }^{1}$}

The paradox of Sepultura's career is that their early career, which encompasses the 1985 EP 'Bestial Devastations', the 1986 album Morbid Visions and the 1987 album Schizophrenia, took place entirely within Brazil. They toured only in Brazil and their records were produced in Brazilian studios by Brazilians for a Brazilian record company. However, they produced music that made no attempt to musically or lyrically signify 'Brazilianness' and their music was consciously modelled on nonBrazilian bands and sung in English. By the time their 1996 album Roots had been released the situation had reversed. They were now based in Phoenix, Arizona, 
recording in non-Brazilian studios for a non-Brazilian company (Roadrunner - an independent multinational based in the Netherlands). Yet the album dealt lyrically with 'Brazilian' themes and incorporated 'Brazilian' musical styles including collaborations with the Amerindian Xavante people and the Salvadoran percussionist Carlinhos Brown.

Sepultura's career can be understood as a trajectory through the 'Extreme Metal Scene'. In using 'scene' as my central unit of analysis, I am drawing on two sets of sources. The first is academic uses of the concept. 'Scene' is closely related to 'subculture', a key concept in the development of popular music studies (e.g., Hebdidge 1979; Willis 1978), the shortcomings of which have been thoroughly discussed and are by now well known (e.g., Clarke 1981; Gelder and Thornton 1997). Subculture connotes a tight-knit, rigidly bounded, implacably 'resistant', maledominated, geographically specific social space (if such formations ever did exist). The concept clashes with contemporary concerns about globalisation, the ambiguities of resistance and the heterogeneity of identity. Scene, on the other hand, connotes a more flexible, loose kind of space within which music is produced; a kind of 'context' for musical practice. It assumes less about the homogeneity and coherence of its constituent activities and members. Although it is frequently used unreflexively, various authors have used scene as their primary unit of analysis (Gaines 1994; Kruse 1993; Shank 1994). There have also been attempts to develop the concept at a more theoretical level (Straw 1991; Olson 1998).

My use of scene also draws on everyday uses of the concept. It is used in a variety of ways in Extreme Metal practice. The most common use of it is to refer to local, face-to-face contexts of music-making and consumption (e.g., 'The Gothenburg Death Metal Scene'). This is similar to academic definitions of subculture. The concept is also used in ways that are similar to academic definitions of scene. 'The Extreme Metal Scene' connotes a decentralised, global and diffuse network of producers and consumers of Extreme Metal. The concept of scene therefore allows us to define a unit of analysis that is emergent both from everyday reflexivity and from a more systematically theorised, academic space.

The Extreme Metal scene emerged in the 1980s out of an interconnected musical and institutional rejection of Heavy Metal. Heavy Metal in the 1980s has been described in detail by Weinstein (1991) and Walser (1993). In that decade it became one of the most successful popular music genres, dominated by a relatively small number of European and American bands. Under the influence of punk, early 1980s bands such as Venom began to develop more radicalised forms of Metal. These forms, including Thrash, Death, Black and Doom Metal, eschewed melody and clear singing in favour of speed, downtuned guitars and growled or screamed vocals. Whilst each style has distinctive features and distinct networks of fans and musicians, they share enough to be frequently referred to by fans and musicians as 'Extreme Metal'. The development of the scene was inseparable from these musical developments. Extreme Metal began to be circulated through letter writing, tape trading, recordings on small labels and fanzines. From a very early stage 'The Underground' (as the scene was then called) was always highly decentralised. Many of its participants never met anybody from it face to face and it was never reliant on local scenes. Moreover, bands from countries outside of the traditional Anglo-American 'core' of the recording industry were influential in its development, including places as diverse as Chile, Malaysia and Israel. 


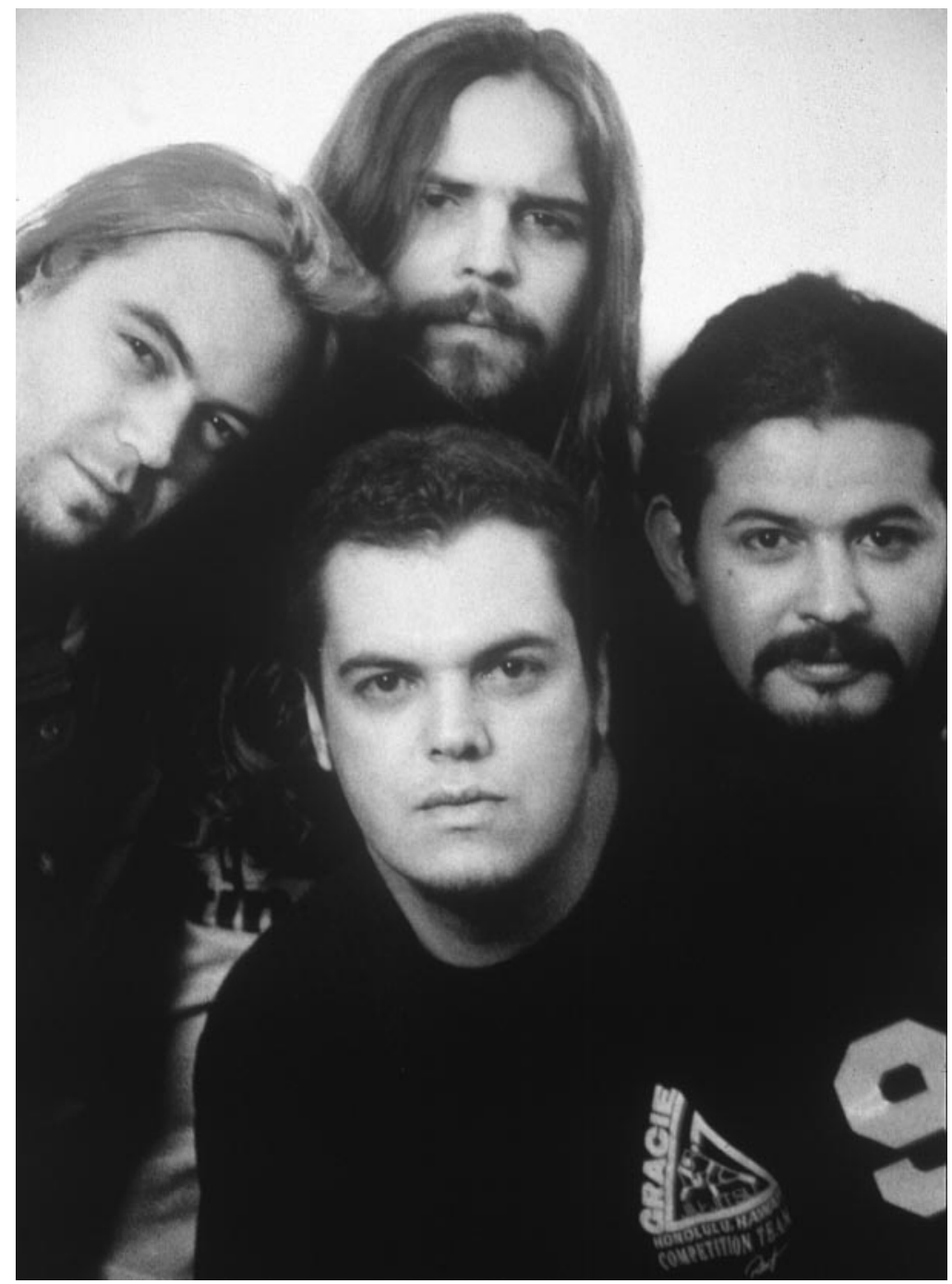

Figure 1. Sepultura at the time of Roots, 1996. Clockwise from top, Andreas, Paolo, Max, Igor

The relationship of the Extreme Metal scene to the wider Metal scene is complex. Until Metallica popularised Thrash Metal in the late 1980s there was little interaction between them. The popularity of Grunge and Death Metal in the early 1990s virtually killed off Heavy Metal as a popular musical form, at least in the sense that few new bands emerged playing that style. However, as the decade progressed, Metal as a mass-market phenomenon was gradually reconstituted through 'New Metal' bands, such as Machine Head and Korn, playing music influenced by Extreme Metal. There is thus some interaction between Extreme Metal and the wider Metal scene that allows one to talk of them as part of the same overall scene, but it is a variable and often tenuous interaction. A major difference is that Extreme Metal is virtually invisible to non-scene members. Whereas Heavy Metal in the 1980s was defined by and to some extent defined itself in relation to, various 


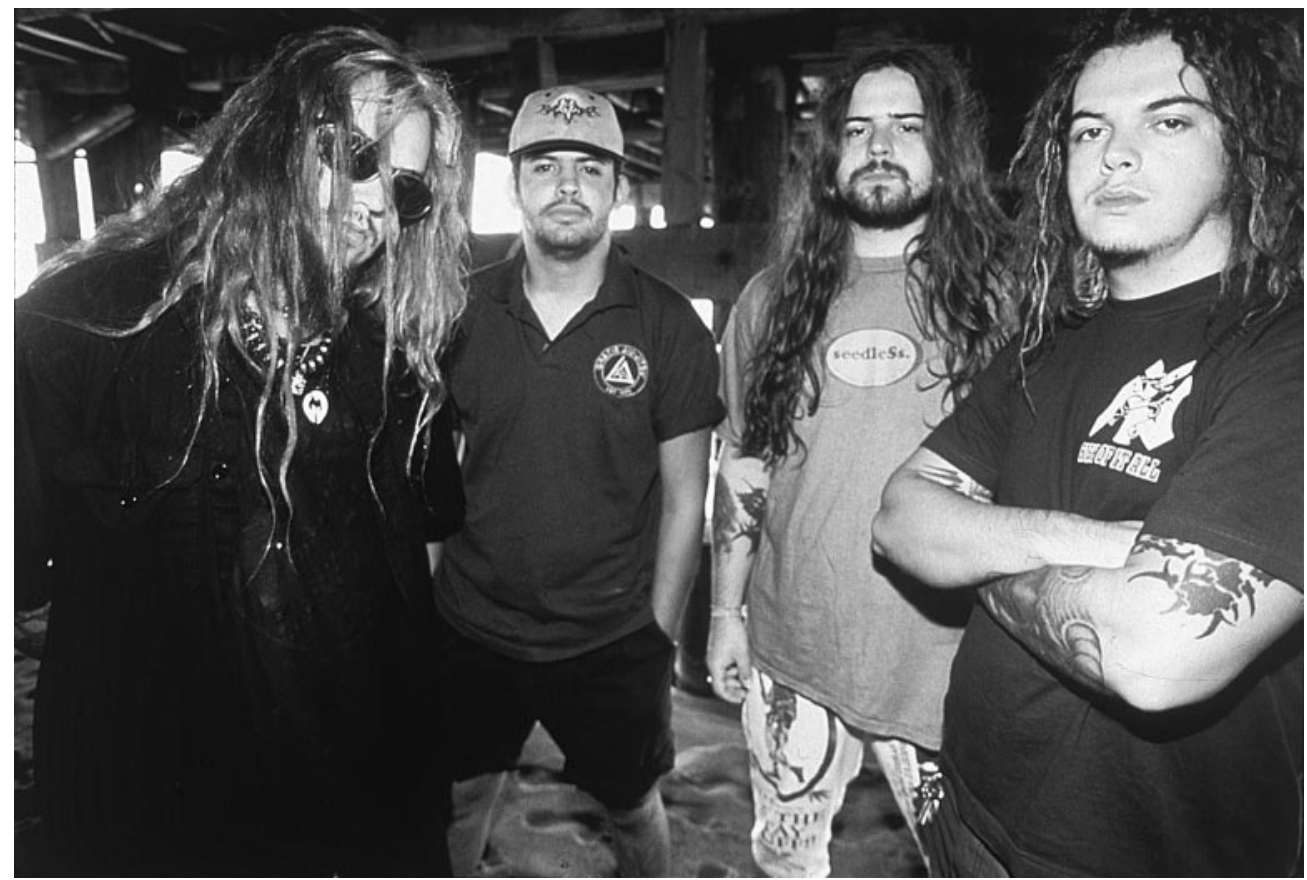

Figure 2. Sepultura at the time of Roots, 1996. Left-right, Max, Paolo, Andreas, Igor

'moral panics' surrounding it, particularly in the United States (Walser 1993), the Extreme Metal scene appears to have had a kind of 'insulation' from these sorts of processes.

Whilst the Extreme Metal scene is characterised by a far greater level of decentralisation than Heavy Metal, local scenes have also been important in its development. Local scenes have been particularly important in pioneering new styles that have gone on to be popular throughout the global scene. In the 1980s, the San Francisco 'Bay Area' scene was crucial in the development of Thrash (involving bands such as Exodus and Metallica). In the late 1980s and early 1990s Death Metal was popularised via strong local scenes in Stockholm (involving bands such as Dismember and Entombed) and Tampa, Florida (involving bands such as Obituary and Deicide). In the mid-1990s Black Metal was popularised through the Norwegian scene (involving bands such as Burzum and Emperor).

Sepultura's early albums, however, are not representative of a uniquely Brazilian Extreme Metal style. Their crude form of Thrash/Death Metal has strong similarities to early Thrash and Death Metal bands such as Sodom and Kreator. The fast drumming dominates everything and gives the guitar riffs an indistinct feel. The gruff vocals are treated with a lot of reverb and brief phrases are spat out rather than sung. The lyrics, written in basic and ungrammatical English, deal with topics such as Satanism and war. One example, 'Bestial Devastation', is shown in Appen$\operatorname{dix}$ A.

It would be easy to conclude that in their early career Sepultura simply copied more prominent Extreme Metal bands from elsewhere in the world. However, from a very early stage Sepultura were not only connected to the global scene, but also contributed to it. Sepultura drummer, Igor Cavalera, reports that early recordings, 
including demos and live tapes, were circulated world-wide by other scene members. Indeed, rehearsal tapes from as early as 1985 are still available on tape trading lists. Sepultura should rather be seen as one of many bands from throughout the world involved in the decentralised process through which the emerging genre of Death Metal was created out of Thrash Metal.

Yet neither should we conclude that Sepultura's location in Brazil was insignificant. Certainly the Brazilian scene from which Sepultura emerged never popularised a particular style in the way more famous local scenes did, but it did have its own unique characteristics. For one thing, the early Brazilian scene was not only marginal to the global Extreme Metal scene, but Western-style rock was at that stage in a non-hegemonic position in the country as a whole (Schreiner 1993). Indeed, the scene was largely confined to Sao Paolo and a few other cities (Sepultura were from Belo Horizonte), and it interacted closely with the punk scene. The unique Brazilian praxis that the band helped to fashion was different from other local praxes worldwide. Moreover, writing Extreme Metal lyrics in English was no easy task. The language barrier was considerable, at least at first. The Portuguese names of early Brazilian bands such as Sarcofago and Holocausto (Sepultura means 'grave') testify to their greater familiarity with their native language. Early lyrics were produced from translating word for word from Portuguese. Singer Max Cavalera's strong accent is very noticeable. It was difficult to purchase good equipment and foreign records due to high import taxes. Brazil's lack of prosperity was also highly significant, with the band coming from struggling lower-middle class families. The Brazilian scene, whilst having its own embryonic institutions, was thus extremely limited in scope in the early to mid-1980s, with only a few shops catering for Metal and a handful of tiny record labels.

Mark Olson (1998, p. 281) argues that scenes are 'territorializing machines' that produce particular kinds of relationships to geographic location. Sepultura's location in their early career was productive of and produced by a certain kind of relationship between global and local scenes. Both scenes were 'quasi-autonomous' from each other in that they were dependant on each other, yet contained practices, texts, institutions and forms of capital that were unique to each. This meant that Sepultura interacted simultaneously within the Brazilian scene and the global scene.

Scenes are never static but are constantly in movement, following particular 'logics of change' (Straw 1991). By the time Sepultura released Schizophrenia in 1987, the global and Brazilian scenes had begun to change. In Brazil, rock music was becoming more popular, partly due to the impact of the annual 'Rock in Rio' festivals. Sepultura now had a predominant position within Brazilian Metal. On the Schizophrenia tour they played to at least 2,000 people every night and sold 10,000 copies of the album, which was as much as more established bands such as Slayer and Anthrax. Globally, Death and Thrash Metal had emerged as standardised genres within a rapidly solidifying set of scenic institutions. Whereas previously the global extreme metal scene had been sustained by a few hundred people linking up isolated local scenes through communication by tape, letter and the occasional record or fanzine, more people were now involved and there were increasing numbers of bands, record companies, fanzines and distribution services. Schizophrenia was widely circulated within the global scene and gave the band a growing international reputation.

Sepultura rapidly began to make contacts throughout the global scene. In 1988, vocalist/guitarist Max Cavalera capitalised on these contacts by flying to New York 
and meeting a number of record companies. This resulted in a deal with Roadracer Records (now Roadrunner). The decision to physically leave the country in order to further the career of the band is revealing. Interviews at the time and since saw the band talking of 'escaping' Brazil and expanding to the global. As Max Cavalera said in an interview with Kerrang in 1989:

It's very difficult because there's almost no chance for a HM band to get on a major label here and also because the Metal crowd is mostly poor people ... Then if you happen to come into some money and want to produce a big show or something like that, the poor people can't afford to pay to come to the show!

How do we explain the decision to look outside Brazil for a deal and other pivotal decisions that Sepultura made in their career? The band came from difficult backgrounds, indeed the Cavalera brothers (Max and drummer Igor) had lost their father in childhood and had to leave school early to support their family (personal communication from interview with Igor Cavalera). It would be easy to explain their burning ambition as the result of a desire to use music to escape these difficult conditions. Such an explanation is not 'wrong' but it does run the risk of an essentialising reductionism. Furthermore, there is also the risk of treating the scene as a static context for action by autonomous agents driven purely by internal psychological factors. I would argue that the concept of scene forces us to focus first on analytically prior 'how' questions - how did Sepultura's career and music progress (Silverman 1993)? The work of Pierre Bourdieu provides a way of linking an analysis of the phenomenology of how decisions are made with an appreciation of the constraining force of structure and capital. For Bourdieu, all practice occurs in 'fields' (1989), a concept with a certain similarity to scene, in which certain forms of capital circulate. The positions that individuals take within fields are guided by their 'habitus' (1993), through which they understand what possibilities are open and closed to them. In this way we can see that the scene limits or opens possibilities to follow particular trajectories. These possibilities are not simply drawn on by individuals or groups, but are continually being reformulated, negotiated and contested. The questions to ask when looking at the career of Sepultura are: what possibilities opened up to them at various times in their career? how did they create their own possibilities? how did these decisions link to the forms of capital available to them? In avoiding the 'why' there is a danger of writing a cultural history that is entirely without agency or motivation. Yet the 'why' may reveal itself indirectly through an appreciation of the 'how'.

From this perspective the most revealing thing about the above quotation from Kerrang is the assumption that going on a major label and putting on a 'big show' would be both desirable and possible. Whilst such sentiments would have been contested by some who valued staying small and 'underground', global success was not problematised within the Extreme Metal scene at that pivotal moment in Sepultura's career to quite the same extent as in other scenes. Sepultura's 'subcultural capital' (Thornton 1995), their prestige and status within the scene, was convertible into other kinds of capital, capital that could bring them financial and institutional support. The career of Sepultura up until and after their signing to Roadrunner was dominated by a particular scenic logic that enabled local scene members to interact within the global underground. However, the possibility of financial rewards and a full time career in music-making was only possible if a band focused more single mindedly on the global scene. 


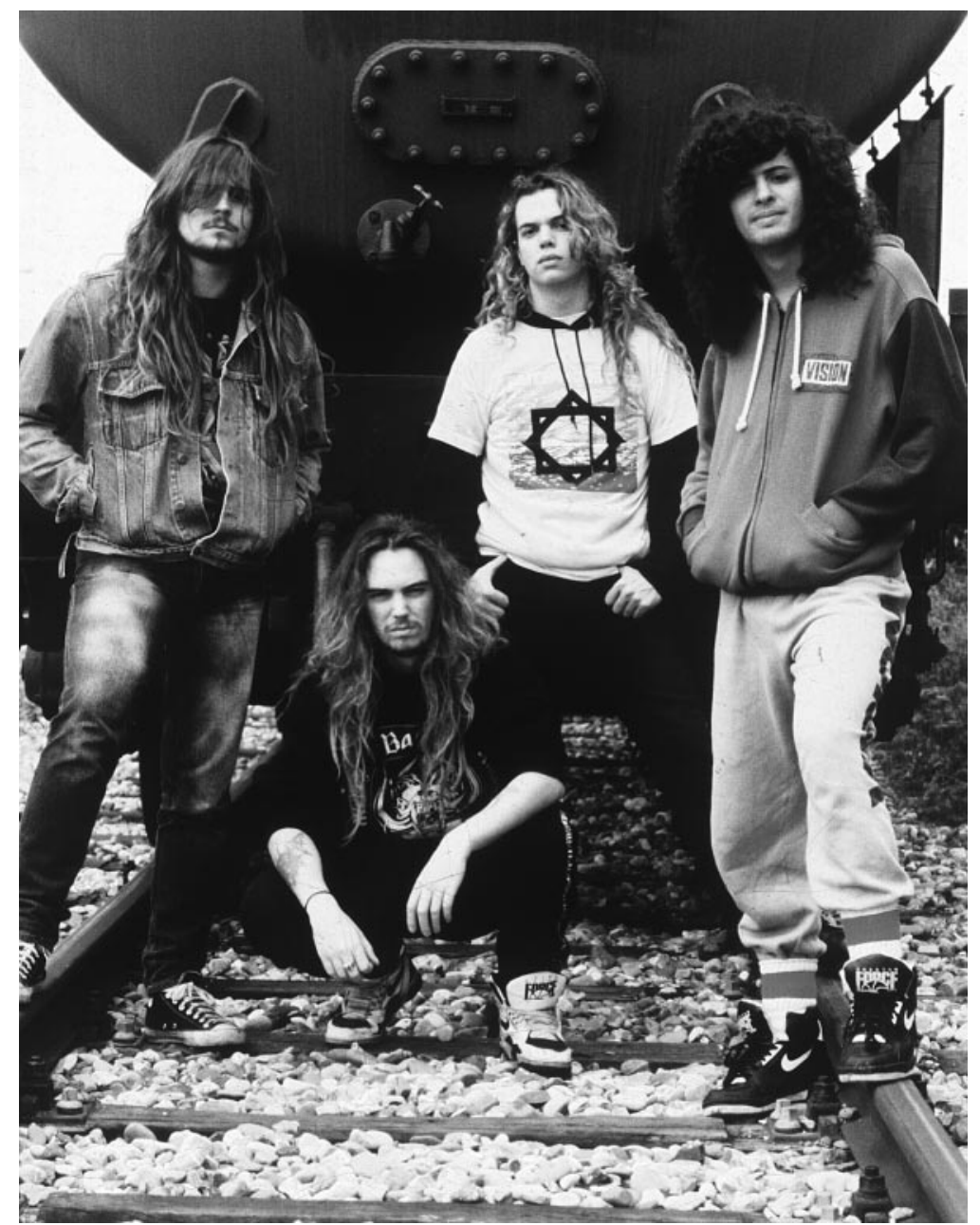

Figure 3. Sepultura at the time of Beneath the Remains, 1989. Left-right, Andreas Kisser, Max Cavalera, Igor Cavalera, Paolo Jr

From 1989 onwards, Sepultura rapidly became one of the most successful bands within Death Metal world-wide. They contributed to the solidifying of Death Metal as a genre with a set of coherent rules and attendant scenic institutions. The 1989 'Beneath the Remains' album was produced in Brazil by the Tampa based producer Scott Burns, who played a crucial part in creating the 'clean', precise guitar sounds that dominated Death Metal in that era. The album was followed by extensive touring throughout the world. The year 1991, when Sepultura released their next album Arise, which was also recorded in Tampa with Scott Burns, was in many ways the 'high watermark' of Death Metal with thousands of bands throughout the world making it the predominant participatory Metal genre. By that stage Sepultura had become leading exponents of Death Metal and were playing major Metal festivals such as Rock in Rio and Donnington. They were helped in this by the 1991 recruitment of Gloria Bujnowski (who later married Max Cavalera) as manager, a woman with considerable experience in managing other Extreme Metal acts. 
In 1991 Sepultura relocated to Bujnowski's hometown of Phoenix. In that period the band were musically and physically at their most distant from Brazil. The Metal press quickly stopped mentioning Sepultura's Brazilianness and treated them like any other prominent Metal band. In most respects, Sepultura had become a leading global Metal band whose connections to Brazil had become less and less salient. Sepultura's trajectory reinforced the trajectory of a global scene within which local scenes produced very similar sounding music and within which place was not musically attended to. Sepultura's success was a key factor in inspiring Death Metal scenes throughout the world, opening up possibilities for bands from marginalised scenes everywhere. At that moment it appeared that the Extreme Metal scene was a truly global space, within which location was musically and institutionally unimportant. As Igor Cavalera puts it

with Sepultura we create something very special which it was like, kind of like a brotherhood where once we start breaking out, people could see like maybe they could do the same. (personal interview, 27 November 1990)

As the 1990s progressed this situation gradually changed. The hegemony of Death Metal within the Extreme Metal scene became eroded with the development of Doom and Black Metal. Moreover, it became more common to produce music that attended to place, cultural origin and nationhood. An important factor in this was the rise of Black Metal from around 1992, in which Scandinavian bands constructed powerful myths of nationhood from ideas of pagan, Viking, anti-Christian ancestry. Some of these bands incorporated 'folk' instruments and styles into their music and drew on Western classical music in order to construct a more 'authentic' sound. This led to a discourse that often crossed into overt racism (Moynihan and Søderlind 1998). This musical construction of place was not confined to Scandinavia, nor to Black Metal. Extreme Metal bands from a diverse set of locations made music drawing on local instrumentation and constructed place in various ways, including the 'Oriental Metal' of the Israeli band Orphaned Land and the 'Salsa Metal' of the Venezuelan band Laberinto.

Sepultura also contributed to this trajectory. The band had occasionally used 'Brazilian' elements such as the 'um, dois, um, dois, tres, quatro' introduction to the song 'Troops Of Doom' on 'Morbid Visions' and a percussion intro to the title track on Arise. There were also occasional lyrics dealing with Brazilian political issues in veiled terms, such as 'Murder' from the album Arise. On the 1993 album Chaos $A D$ the band began systematically, musically and lyrically to incorporate a greater element of 'Brazilianness'. Additional percussion was used on the song 'Refuse/Resist' and the drumming throughout the album focused on the toms more. The bonus track on the CD is a cover of the song 'Policia' by the Brazilian band Titas and is sung in the original Portuguese. The instrumental track 'Kaiowas' is dedicated to an Amerindian tribe who committed mass suicide as a protest against land expropriation, and the songs 'Manifest' and 'Biotech Is Godzilla' also deal with Brazilian issues.

But it was in the 1996 album Roots that the most concerted attempt to signify Brazilianness was made. Whereas previous albums had focused on oppression within Brazil, the Roots album wields 'Brazil' as a positive musical and symbolic resource. As Max Cavalera is quoted as saying on the press release accompanying the album: 'I wanted to show some parts of Brazil that were artistic, rather than just songs about street kids and government corruption'. 


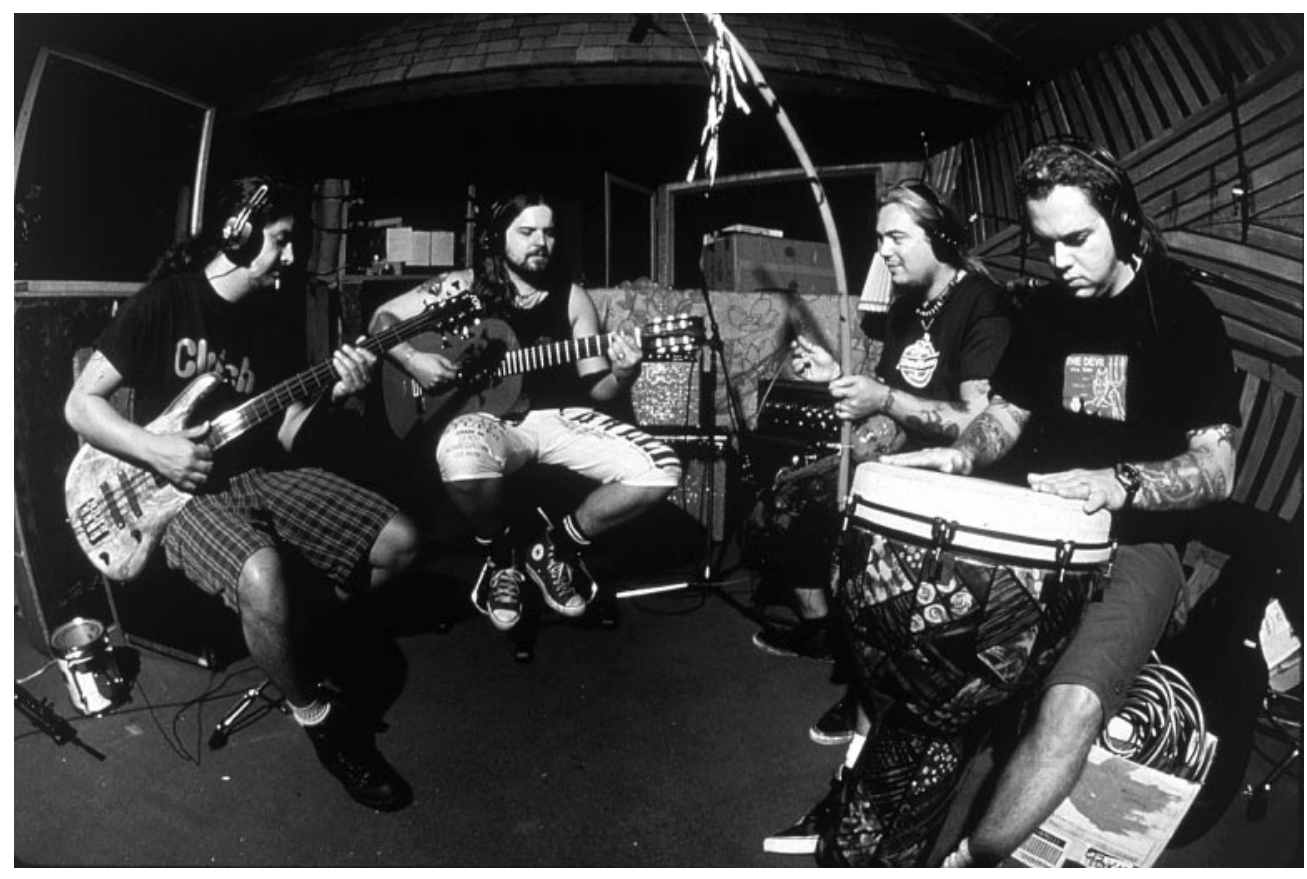

Figure 4. Sepultura recording Roots, 1996. Left-right, Andreas Kisser, Max Cavalera, Igor Cavalera, Paolo Jr

The demands of extremity and heaviness are refracted through the idea of Roots. It is an idea that draws on the power of tradition and community as well as the pain and oppression of Brazilian history. The lyrics speak of constant struggle but struggle through which 'We're growing stronger everyday, stronger in every way' ('Roots Bloody Roots') and that despite everything 'These roots will always remain' ('Born Stubborn'). The music has also changed from their earlier speedobsessed Thrash with clean guitar sounds. On Roots heavily downtuned guitars (low E tuned to B or D) create an oppressive, almost drone-like effect over Igor Cavalera's drumming that is pushed high in the mix and relies on the toms as much as bass, snare and hi-hat. Much of the album was recorded using analogue equipment and many of the tracks were the result of extended 'jams'. Max Cavalera's vocals are often distorted, underlining the oppressive feeling. To this claustrophobic mixture on various tracks is added Brazilian percussion instruments and on one track ('Attitude') the 'Berimbau' - a stringed instrument of Afro-Brazilian origin. These instruments are deployed in such a way that they do not jar. They rather create a pummelling, reinforcing effect that adds to the extreme mixture. This can intensify the claustrophobia (as in 'Attitude') but can also create moments of 'rising above' despite everything. The latter is the case in the ecstatic collaboration with the percussionist Carlinhos Brown on the track 'Ratamahatta' that features a bizarre mixture of Death Metal and Brazilian, Salvadoran Carnival percussion (djembe, lateria, surdo and others). The lyrics (see Appendix B) joyously celebrate shanty town life and Brazilian outlaws and folk heroes Ze Do Caixo and Lampiao. The collaboration with the Xavante tribe of Pimentel Barbosa surfaces on two tracks - 'Born Stubborn' and 'Itsari'. On the former, a recording of the 'Wana Rido-

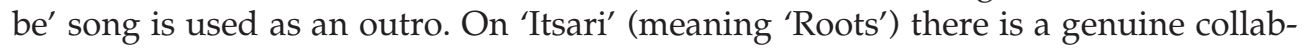


oration with Sepultura improvising on acoustic guitars and percussion over the 'Datsi Wawere' healing chant.

Roots refracts the concerns of a global music scene through a lens of a particular construction of Brazilianness. The 'roots' returned to are not tokenistic incorporations of an exotic 'other' to prop up a moribund music, but a resource to be learned from that is part of Sepultura who are also part of a wider, global scene. Moreover, the members of Sepultura had grown up listening to and playing Brazilian music indeed the Cavalera brothers were members of a samba school. Nor are roots seen as autochthonous and bounded, but multi-ethnic syncretic and complex:

... we're showing some of the best parts of our country, the colours, the culture and music of the Indians, the African influence with all the percussion and things like that. So we've shown some of those roots, the music of Brazil, and our own roots too - the big cities where we come from, the urban metal style. (Interview with Andreas Kisser, Terrorizer 37, November 1996)

In many ways then, Roots has a lot in common with the work of other Brazilian musicians such as Chico Science, who have attempted to syncretise various Brazilian musics with contemporary rock music (McGowan and Pessanha 1998)

Like all such projects, Roots has its problems. Whilst the Xavante appear to have been treated with respect and receive royalties, it is unclear how they understood the project and what they will get out of it. The Xavante had little say on how the piece was set within the album (although 'Itsari' was not overdubbed at all). Neither can Sepultura ensure that those who purchase their albums will not exoticise the Brazilianness in the project. Nonetheless, Sepultura did approach Roots in a spirit of discovery that avoids many of the pitfalls that other artists have fallen into in such projects. The collaboration was not intended simply to add exotic 'colour' to their music, but was a sincere (if perhaps naïve) attempt to collaborate

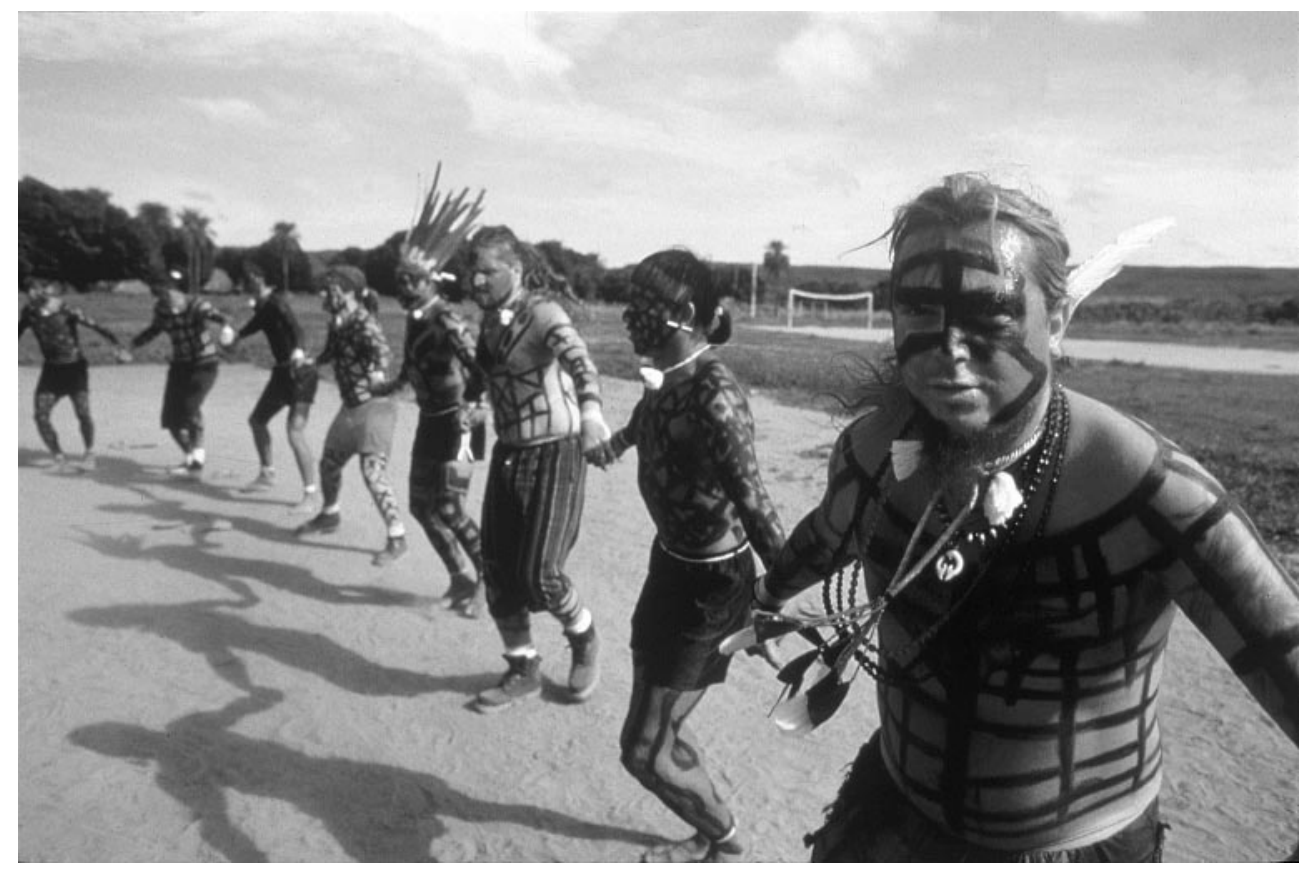

Figure 5. Sepultura recording with Xavanta tribe, Pimentel Barbosa, Brazil, 1996 
and learn from Sepultura's fellow Brazilians. Moreover, the Xavante of Pimentel Barbosa have become skilled at dealing with non-Xavante Brazilians and nonBrazilians (Graham 1995) and Cipasse, the president of the Xavante of Pimentel Barbosa and Sepultura's primary contact, had toured with Milton Nascimiento. The Xavante also released a statement warmly commending the collaboration (http://sepultribe.com/rev/se_info01.html).

Yet there are many tracks on the album that make no attempt to construct Brazilianness. There are collaborations on the album with Western musicians, such as DJ Lethal of House of Pain and Jonathan Davis of Korn. Sepultura and its constituent members have collaborated with a variety of musicians since the early 1990s. In 1994 Max Cavalera released an industrial album with Alex Newport of the British band Fudgetunnel under the name of Nailbomb. Sepultura have also drawn on a wide variety of other musical resources that have no connection with Brazil. For instance, the intro to the Chaos $A D$ album contains a recording of Max Cavalera's son Zyon's heartbeat in his mother's womb.

Once again there are no easy explanations as to why Sepultura began to experiment with Death Metal, and particularly why they began to use Brazil as a musical and lyrical resource. What is clear is that Sepultura's success in the early 1990s in producing 'placeless' Death Metal left Sepultura with the capital to be able to experiment widely with whoever and whatever they wished. Sepultura's record sales grew from 600,000 for 'Beneath the Remains' to over 1,200,000 for Roots. The more success Sepultura have achieved, the more removed they have become from the Brazilian scenic infrastructure, but also the more able they have been to play with new musical possibilities. So global success enabled experimentation with new 'local' and other syncretisms as much as it distanced them from the brute facts of location. Yet it is important to note that other Death Metal bands that achieved success at the time Sepultura did, such as Obituary or Cannibal Corpse, did not experiment with place and other musical resources.

In December 1996 Sepultura unexpectedly split up. The reasons appear to have nothing to do with their musical style but with the tensions between Max and Gloria Cavalera and the rest of the band. Early in 1998 Max Cavalera returned with a band and eponymous album called Soulfly. As on Roots, several of its songs feature lyrics on Brazilian themes or written in Portuguese, and a number also feature Brazilian instruments. It also features several guest musicians including members of Fear Factory, Limp Bizkit and Dub War. Later in 1998 Sepultura also released an album, Against, with the Afro-American vocalist Derrick Green, who had taken over from Max Cavalera. Unlike Soulfly, the 'Brazilian' content of the album is less than on Roots, although there is considerable use of percussion. As on Soulfly there is extensive use of guest musicians including a collaboration with Japanese Kodo drummers on 'Kamaitachi'.

Both bands (particularly Soulfly) seem to be moving towards a hybrid form of Metal influenced by punk, rap and funk. It is a music for a transglobal oppressed 'other', refracted through Brazil. This was always a feature of Sepultura's work. For example, the video for 'Refuse/Resists' from Chaos AD contains footage of riots and police brutality world-wide. The band have made consistent efforts to tour countries where few Extreme Metal bands play, such as Indonesia and New Zealand. As Igor Cavalera puts it: ' . . . someone in Israel someone in Japan always related Sepultura not only because of Brazil but the fact that ... Sepultura represents all those countries in a way' (personal interview, 27 November 1998). 
This resolutely global attitude has brought with it the danger of Sepultura and Soulfly falling into a crude global postmodernism. Their voracious desire to experiment is problematic. In an interview with Metal Hammer in October 1998, Igor Cavalera is quoted as saying:

We've thought about hooking up with the aborigines in Australia cos they make a fucking excellent atmospheric and moody music with the digderidoo. All the world's tribes have so many connections in rhythm and that lends itself to our music very well.

Here global difference is reduced to a set of undifferentiated, exoticised 'tribes'. Sepultura and Soulfly have come to walk the narrow line trodden by a number of artists who have sought to experiment and collaborate with a variety of cultures, such as Peter Gabriel and Paul Simon.

This problematic 'rootlessness' has also taken both bands further away from the Extreme Metal scene and into a more complex space within the wider Metal scene. The late 1990s has been a time of major change in Metal. There has been an increasing cleavage between the (mostly American) 'New Metal' bands, such as Korn that are introducing new elements into Metal and have achieved considerable mass market success, and an increasingly 'fundamentalist', Extreme Metal scene. The musical freedom of the 'New Metal' scene, is accompanied by an extremely loose set of scenic constraints. Sepultura and Soulfly have shown themselves in interviews to be relatively uninterested in the contemporary Extreme Metal scene. In Guitar Magazine at the time of Roots, Max Cavalera criticises contemporary Death Metal: ' . . When I first listened to Death Metal it stood for rebellion and I thought it was really interesting. Today though, it's almost like a fashion trend ... it's not true any more, it's totally fake' (vol. 6, no. 4).

Here Cavalera proclaims his autonomy and in doing so reinforces his new position within a scene that places minimal institutional constraints. Sepultura and Soulfly may have returned to Brazilian 'roots', but they have radically weakened their commitment to the institutional roots in the scene within which they developed. Their gaining of financial and cultural capital within a looser scene has led to their losing capital within the Extreme Metal scene. It seems that a major impetus in guiding Sepultura's trajectory from Chaos $A D$ onwards was a desire to assert musical and institutional autonomy from the scene that spawned them. As Igor Cavalera explains with regard to Roots: 'we were like ... what can we bring out of our own music, that is the Brazilian influence, that can make our music stand out more than its ever been' (personal interview, 27 November 1998).

Yet there are still continuities with their past. Both Sepultura and Soufly remain on Roadrunner Records. At concerts both bands play songs from throughout Sepultura's career and play on bills with Extreme Metal acts. Moreover, Brazil is not simply one more 'exotic' resource to draw on amongst many others. Both bands have remained politically engaged within Brazil throughout the 1990s. Sepultura and Soulfly have produced lyrics about Brazilian political issues and have come out in support of Brazilian groups such as Tortura Nunca Mais ('Torture Never Again'). Their outspoken statements against the police have caused them trouble, leading to Max Cavalera's arrest after allegedly spitting on the Brazilian flag after a show in Sao Paolo in 1994 (he was later released without charge). Soulfly included an address in their CD for a pressure group to stop the destruction of the rainforest. In August 1998 Sepultura played a show to 20,000 people in Sao Paulo called 'Noise Against Hunger' for which everyone attending had to bring one kilogramme of 
food. The bands are 'stars' in Brazil as nowhere else - Max Cavalera has even been asked to score a Brazilian commercial for Sprite. This has continued despite both bands incorporating non-Brazilian musicians into their bands. 'Brazil' then, adds some 'weight' and fixity to a band becoming radically globalised. It remains a place to which Sepultura and Soulfly members have 'real' links - family, friends, history, etc. Moreover, whilst Max Cavalera still lives in Phoenix, the rest of Sepultura are now spending more and more time in Brazil (even Derrick Green is learning Portuguese). The discursive and the real reinforce each other to make Brazil an important anchor in their complex trajectories.

\section{The implications of scene}

This brief history of Sepultura's career uses the concept of scene in a number of ways. In this section I want to expand some of the implications of the ways that I have used the concept. The most striking thing about Sepultura's career is the number of scenes they were part of - the Brazilian Metal scene, the Death Metal scene, the global Extreme Metal scene, the global Heavy Metal scene. These scenes exist quasi-autonomously within each other and effect each other's and Sepultura's trajectories. Sepultura can never be unproblematically placed once and for all within one single scene. Neither can they escape scenes completely - even in their later period in which capital gave them a certain autonomy, they were part of scenes. Yet as well as being productive of Sepultura, scenes are also produced by them. In their early career, Sepultura's success from a marginal scene changed expectations of what was institutionally possible within the global scene. In their later career they changed ideas of what was musically possible within Death Metal.

It is but a short step to arguing that all music and music-related activity takes place within a scene or scenes. This assertion allows us to avoid the endless task of drawing boundaries between what is a scene and what is not. It recognises that no musical practice can take place entirely separately from social processes. The implication is that scenes include everything, from tight-knit local musical communities to isolated musicians and occasional fans, since all contribute to and feed off a larger space(s) of musical practice. Even the simple action of buying a CD means to become 'involved' in a scene, in however slight a way, by virtue of causing some sort of effect within it. One cannot make a rigid distinction between 'active' and 'passive' membership. It also follows that everything within a scene, and indeed scenes themselves, may exist within a number of other scenes. A musical text, for example, may circulate within a number of scenes at once. Moreover, texts and individuals may move on a variety of trajectories through scenes along particular 'pathways' (Finnegan 1989) through life. Similarly, scenes themselves are constantly shifting, splitting and combining - any stability can only be momentary.

\section{The potentials and problems of the Extreme Metal scene}

In the introductory paragraphs to this paper, I argued that it was important to understand processes of globalisation in music in ways that would allow us to appreciate the specificities and paradoxes of particular cases, whilst relating them to general global processes and structures. As we have seen, the concept of the scene allows us to examine the ways in which Sepultura's trajectory was produced 
by and productive of particular global-local relations. The case of Sepultura resists simple global-local dichotomies. Instead, at particular points in their career, their position within the scene enabled different ways of responding to their position within Brazil and the world. What might Sepultura tell us about the potentials and problems of the globalisation of music?

Music is deeply implicated in the construction of place and individual and group identities are tied into this construction. Martin Stokes has shown how music in various locations 'evokes and organises collective memories and present experiences of place with an intensity, power and simplicity unmatched by any other social activity' (1994, p. 13). What rap music in the ghettos of New York, indie music in Liverpool and juju in Nigeria (my examples) have in common, is 'to encourage people to feel that they are in touch with an essential part of themselves, their emotions and their community' (ibid., p. 13). Industrialisation and globalisation have made available an increasingly large range of musical resources that have enabled a growing range of groups and individuals to use them in the construction of identity and location.

The very mobility and malleability of music that makes it such a potent tool in empowering people to respond to their location in the world is of course the result of 'flows' (Lash and Urry 1994) of various forms of capital. These flows result in severe inequalities in the ability of groups to appropriate and distribute music. However much people may feel that a particular music is essentially 'theirs', any exclusive sense of musical ownership is permanently under threat. Western artists may appropriate non-Western musics in ways that trivialise or exoticise them in the dilettante search for new musical materials. Global musical flows are facilitated by multinational corporations able to wield substantial financial and other resources. The international state system also effects global flows of music. This can work either through straightforward means such as censorship, or in more complex ways such as the uneven implementation of copyright law. What is intertextuality to some, is straightforward stealing to those who do not have recourse to copyright and capital. Of course, subordinate groups do often appropriate music themselves and sometimes do penetrate other musical markets, but in broad terms the interlinkage of musical and capital flows is highly problematic.

Thus a vision of what sort of musical texts we would like to see in a world in which processes of globalisation are inescapable, must bear in mind both the ability of music to enable people to 'penetrate' their locations in the world and the inability of music to transcend global flows of capital and power. It is important to try to envisage a global musical practice as free as possible from large differentials of capital, that would reconcile the deep emotional investments in ideas of ownership stemming from the musical construction of place, with the fact that music can and will travel. This practice should enable the circulation of music and yet still allow for the penetration of locality, identity and ownership in unique, but nonessentialising ways.

An examination of the career of Sepultura within the Extreme Metal scene provides one way of assessing whether the scene might provide a model for this global musical practice. Certainly, in their later work Sepultura and Soulfly have mostly managed to avoid the pitfalls of an excessively dilettante practice. Their Brazil is more than a crudely deployed signifier or a rigidly policed 'authentic' discourse. It is rather a hybrid and flexible concatenation of the discursive and the real that continually links the global and the local. Sepultura 
and Soulfly have managed to penetrate locality, identity and musical ownership in a complex and non-essentialist manner whilst becoming the embodiment of globally located artists.

Yet the position from which they are producing this music is, in the last analysis, a highly privileged and capital-rich position. Although they have made concerted attempts to retain Brazilian connections, the connections are those of privileged migrants who can leave whenever they wish. The global Extreme Metal scene enabled them to achieve this position through its exceptional decentralisation in the 1980s and early 1990s. It remains unlikely today that a Brazilian Metal (or indeed rock) band could achieve global prominence in any other way than through such a scene. Yet at the time the scene was accompanied by a musical practice that did not treat place as a musical resource. Although today place is a musical resource within the scene, it is generally constructed in essentialist, sometimes racist ways. For all its global decentralisation, there is intense ambivalence within the scene towards more complex and ambiguous penetrations of the global and the local. Roots, together with Sepultura and Soulfly's subsequent work, was made possible by a more unencumbered position within a wider Metal scene that challenged global flows of capital far less. Moreover, the widening gap between the resurgent Metal scene and the Extreme Metal scene means that the latter is becoming ever less willing and able to learn from Sepultura's musical example.

All that said, the Extreme Metal scene is far closer to the global musical practice we are looking for than are many other scenes. At its best, it allows bands such as Sepultura to galvanise musicians and fans across the world yet still attend to local specificity. As Regev (1997) has argued, such 'reflexive communities' (Lash 1994) have the potential to provide temporary resolutions to the apparent contradiction between participation in the field of (global) popular music and the field of local/national identity. The scene also enables members across the world to interact on a fairly equal basis. The scene has the potential to avoid both the tight restrictions of traditional musical subcultures and the anomie of isolated musical occurrences facilitated by large multinationals.

In a similar way, a 'scenic methodology' re-contextualises musical texts, institutions and practices within the social spaces in which they are enmeshed. It provides an alternative both to atomising forms of research that ignore wider contexts of music production and consumption, and to forms of research that overdetermine those contexts in 'subcultural' frameworks. The concept allows us to build ideal types in the search for models for a global musical culture. The theoretical and methodological moves involved in developing the concept of the scene can thus provide new ways of thinking about globalisation and music.

\title{
Appendix A: 'Bestial Devastation' lyrics
}

(Spelling, grammar and punctuation as shown on lyric sheet)

\author{
A legion of demon's \\ Born from the boundaries of death \\ Like a onslaught of evil \\ To destroy this earth \\ Covering the morbid skys \\ Like a mist of sulphur
}


I can see Satanas

The cursed of death

Terminate masse's and reigns

With blood axe's of hate

The beast of son of evil

Tormenting the preacher of Christ

The human's try to react

To this nuclear war

Wich is like a endless pain

Burning in the fire of hell

\section{Appendix B: 'Ratamahatta' lyrics}

Biboca ['Dive']

Garagem ['Garage']

Favela ['Slum']

Fubonga ['Hoodlum']

Maloca ['Shanty']

Bocada ['Ghetto']

Maloca

Bocada

Fubanga

Favela

Garagem

Biboca

Porra! ['Fuck']

Ze Do Caixao

Zumbi

Lampiao

Hello Uptown

Hello Downtown

Hello Trenchtown

Ratamahatta!

Hello Uptown

Hello Downtown

Hello Midtown

Hello Trenchtown

Ratamahatta!

\section{Acknowledgements}

I would like to thank Dave Hesmondhalgh, Chris Jenks and Sara Cohen for helpful comments on this paper, Michelle Kerr at Roadrunner for giving me access to her archives and other help and Igor Cavalera for the interview. I would also like to thank those who commented on my papers at the July 1997 IASPM conference in Kanazawa and the July 1997 Open University Music and Cultural Difference conference in London. Lyrics are reprinted by kind permission of Roadblock Music Inc. 


\section{Endnote}

1. The sections on the Extreme Metal scene and Sepultura draw on ongoing doctoral research. I have also surveyed UK music press coverage of the band from 1989 to 1996 and conducted an interview with drummer Igor Cavalera.
Unfortunately, some of the cuttings were not properly referenced. When quoting from such sources, I have given as much information as was available.

\section{References}

Bourdieu, P. 1989. Outline of a Theory of Practice (Cambridge) 1993. The Field of Cultural Production (Oxford)

Clark, G. 1981. 'Defending ski-jumpers: a critique of theories of youth subcultures', in On Record: Rock, Pop and the Written Word, eds. S. Frith and A. Goodwin (London), pp. 81-96

Featherstone, Mike (ed.) 1990. Global Culture: Nationalism, Globalisation and Modernity (London)

Feld, S. 1994. 'Notes on 'World Beat', in Music Grooves: Essays and Dialogues, eds C. Keil and S. Feld (Chicago)

Finnegan, R. 1989. The Hidden Musicians: Music-Making in an English Town (Cambridge)

Gaines, D. 1994. 'The local economy of suburban scenes', in Adolescents and their Music: If it's too Loud, You're too Old, ed. J. Epstein (London), pp. 47-66

Gelder, K. and Thornton, S. (eds) 1997. The Subcultures Reader (London)

Graham, L. G. 1995. Performing Dreams: Discourses of Immortality Among the Xavante of Central Brazil (Austin)

Hebdidge, D. 1979. Subculture: The Meaning of Style (London)

Kruse, H. 1993. 'Subcultural identity in alternative music culture', Popular Music, 12, pp. 33-43

Laing, D. 1986. 'The music industry and the 'cultural imperialism' thesis', Media, Culture and Society, 8, pp. 331-41

Lash, S. 1994. 'Reflexivity and its doubles: structures, aesthetics, community', in Reflexive Modernisation, eds U. Beck, A. Giddens and S. Lash (Cambridge), pp. 110-73

Lash, S. and Urry, J. 1994. Economies of Signs and Space (London)

Lipsitz, G. 1994. Dangerous Crossroads: Popular Music, Postmodernism and the Poetics of Place (London)

McGowan, C. and Pessanha, R. 1998. The Brazilian Sound: Samba, Bossa Nova and the Popular Music of Brazil (Philadelphia)

Mitchell, T. 1996. Popular Music and Local Identity: Rock, Pop and Rap in Europe and Oceania (London)

Moynihan, M. and Søderlind, D. 1998. Lords Of Chaos: The Bloody Rise of the Satanic Metal Underground (Venice, CA)

Olson, M. 1998. 'Everybody loves our town: scenes, spatiality, migrancy', in Mapping the Beat: Contemporary Music and Contemporary Theory, eds T. Swiss et al. (Oxford), pp. 269-90

Regev, M. 1997. 'Rock aesthetics and musics of the world', Theory, Culture and Society, 14, pp. 125-42

Schreiner, C. 1993. Musica Brasileira: A History of Popular Music and the People of Brazil (London)

Shank, B. 1994. Dissonant Identities: The Rock $n$ Roll Scene in Austin, Texas (Hanover)

Silverman, D. 1993. Interpreting Qualitative Data: Methods for Analysing Talk, Text and Interaction (London)

Slobin, M. 1993. Subcultural Sounds: Micromusics of the West (Hanover)

Stokes, M. (ed.) 1994. Ethnicity, Identity and Music: The Musical Construction of Place (Oxford)

Straw, W. 1991. 'Systems of articulation, logics of change: communities and scenes in popular music', Cultural Studies, 5, pp. 368-88

Taylor, T.D. 1997. Global Pop: World Music, World Markets (London)

Thornton, S. 1995. Club Cultures (Cambridge)

Walser, R. 1993. Running with the Devil: Power, Gender and Madness in Heavy Metal Music (Hanover)

Weinstein, D. 1991. Heavy Metal: A Cultural Sociology (New York)

Willis, P. 1978. Profane Culture (London)

\section{Discography}

Nailbomb, Point Blank. Roadrunner Records, RR-9055-4

Sepultura, Morbid Visions/Bestial Devastation. Roadrunner Records, CD RR 87652 
Sepultura, Schizophrenia. Roadrunner records,CD RR 87642.

(NB: The above two are re-releases originally put out by Cogumelo Producoes in 1985, 1986 and 1987)

Sepultura, Beneath the Remains. Roadrunner Records, CD RR 8766 2. 1989

Sepultura, Arise. Roadrunner Records, RO-9328-1. 1991

Sepultura, Chaos A.D., Roadrunner Records, RR-9000-5. 1993

Sepultura, Roots. Roadrunner Records. RR-8900-5. 1996

Sepultura, Against. Roadrunner Records, RR 8700 2/4. 1998

Soulfly, Soulfly. Roadrunner Records, 1RR 8748-2. 1998 